\title{
V INTERNATIONAL UNIVEST CONFERENCE: THE CHALLENGES OF IMPROVING ASSESSMENT
}

\section{Organizing Committee UNIVEST'15}

University of Girona (Spain)

univest@udg.edu

\author{
Beatriz Amante Garcia ${ }^{D}$, María Martínez Martínez ${ }^{D}$ \\ Universitat Politècnica de Catalunya (Spain) \\ info@jotse.org
}

\begin{abstract}
The V International UNIVEST Conference aimed to provide an integrative and critical outlook on the assessment process, considering it as an activity integrated in general university teaching, with the active participation of all subjects involved at all educational stages. With that main goal, the emphasis in this edition was on creating a forum to debate and exchange ideas about university teaching and learning processes and the importance of placing students in the centre of those processes.
\end{abstract}

Keywords - Assessment, active participation, university teaching, learning processes, univest15

\section{Editorial}

After four editions in which the work of UNIVEST had focused on collaborative learning, the selfregulation of learning, student involvement in the university and students as axis of change in the university, this fifth edition aimed to provide an integrative and critical outlook on the assessment process. Assessment, understood as an activity integrated in general university teaching, with the active participation of all subjects involved at all educational stages. With that main goal, the V International UNIVEST Conference was proposed as a forum to debate and exchange ideas about university 
teaching and learning processes and the importance of placing students in the centre of those processes.

Like the previous editions, this one was committed to an especially participatory working dynamic and to promoting different points of view. The scheduled debates were complemented by contributions from recognized specialists who shared their ideas and thoughts about how to improve the assessment process.

In relation to this general subject, papers were specifically focused on one of the five central themes proposed for this edition:

- $\quad$ Student assessment

- Teacher assessment

- Institutional assessment

- Student participation

- Planning and organization of teaching

- Experiences outside the classroom

A total of 34 papers in the sciences, engineering and architecture were accepted by the Scientific Committee of the Conference. Every paper was reviewed by at least two reviewers. The possibility of submitting their papers to the Journal of Technology and Science Education (JOTSE) was offered by the organization to the authors with highest rated communications in these areas.

A set of five papers was finally selected for publication in this special issue of JOTSE. The study "On-line quizzes to evaluate comprehension and integration skills" shows the use of Socrative, a 2.0 tool, to assess one of the transversal competences, "understanding and integration", identified by the Polytechnic University of Valencia as one of the most important. The results show that students are very satisfied with Socrative as an element that enhances active participation and the acquisition of the transversal skills of understanding and integration, suggesting its use may be extended to other subjects.

"The use of technology in a model of formative assessment" presents a model of formative assessment for a course of mathematical analysis conducted by Engineering students of Polytechnic University of Madrid. It includes online quizzes with feedback, a portfolio with weekly deliveries, tests that use mathematical software and a group project. The model has been debugged since 2009 and during 2014-2015 it was added as a pilot project to create a virtual 
learning community based on Google+. Among other things, it has been used in an experimental peer evaluation of projects by students.

The article "Proposals for improving assessment systems in higher education: An approach from the model "Working with People"" shows the process carried out by the Technical University of Madrid (UPM) to analyse assessment systems and the ways to improve them, in both bachelor's and master's degree programmes. The methodology used is based on the model "Working with People", which, for the first time at the UPM, creates a participatory process aimed at knowing students' and lecturers' opinions and feelings about the assessment process and the potential for improvement. The results indicate that their respective perceptions of the assessment systems have many common points and underscore the need for a strategy to improve the integration of actions from all dimensions of the model and achieve a balance of collaborative work among lecturers, university administrators and students.

"The development of professional skills competences using the interdisciplinary project approach with university students" describes the experience of a group of teachers from various departments of the University of Girona based on the need for interdisciplinary work in university classrooms to enhance relevant skills of the professional field. In this experience, students from different grades developed a collaborative and interdisciplinary project to manage a school canteen. This work enhanced the development of key skills for today's professional world (for example, working in multi-professional teams) that are difficult to acquire through activities without an interdisciplinary approach.

The article "Learning based on the project entitled "Design and construction of a wooden bridge" presents the results of a project-based learning activity conducted by Mechanical Engineering students of the University of Girona. This project requires students to address, formulate and solve various problems related to the strength of materials, structural calculations, optimization of materials and structural design. The project also includes the construction of a bridge. Finally, a competition is held to reward teams that have achieved obtained a better ratio between the load and the weight of the bridge. The main findings of this project are that students acquire specific skills and transversal competences and are increasingly motivated by the topic.

The Organizing Committee of the 5th International UNIVEST Conference acknowledges the Editorial Board of the Journal of Technology and Science Education (JOTSE) for publishing this special issue on improving assessment strategies. 


\section{Organizing Committee of UNIVEST'15}

Dr Rafael García Campos, Director of the Josep Pallach Institute of Education Sciences, UdG Dr Xavier Cufí Solé, Head of Unit of the Josep Pallach Institute of Education Sciences, UdG Ms Margarida Falgàs Isern, Head of Unit of the Josep Pallach Institute of Education Sciences, $\mathrm{UdG}$

Ms Rita Barnés Ros, Administrator of the Josep Pallach Institute of Education Sciences, UdG Ms Sílvia Aznar Suñer, Educational Innovation Specialist of the Josep Pallach Institute of Education Sciences, UdG

Dr Isabel Villaescusa Gil, Polytechnic School, UdG

Dr Silvia Font Mayolas, Vice-Rector for Students, UdG

Dr Francesc Roca Urgell, Vice-Rector for Academic Policy and Teaching, UdG

Mr Aitor Palomares Lozano, Student Council, UdG

Dr Gerard Arbat, Coordinator of the Network of Educational Innovation in Evaluation, UdG 